\title{
Climate change governance in agroforestry systems: a systematic review
}

\author{
Pamela Katic
}

\begin{abstract}
Agroforestry has the potential to fundamentally transform socio-ecological systems to address the root causes of climate vulnerability. Although there is increasing interest in agroforestry as a transformative adaptation strategy, its implementation is often discouraged by the need to involve multiple stakeholders, sectors, and governance levels with potentially different interests. We draw on a systematic review of sixty-four peer-reviewed papers on climate change governance in agroforestry systems to (1) outline the current state of the literature, (2) characterise how governance is conceptualised, (3) investigate governance challenges, and (4) provide insights into effective governance. The review finds that most relevant papers have been published in the past three years, and most of these papers are found in interdisciplinary journals. The main governance challenges include coordinating polycentricity, overcoming power imbalances, and sharing, translating, and integrating different types of knowledge. However, few empirical studies of agroforestry governance have been completed. A richer conceptual framework of governance is required to improve our ability to navigate the role of sustainable land management practices such as agroforestry in successful climate change adaptation and mitigation.
\end{abstract}

Keywords: Governance, agroforestry, climate change, socio-ecological systems, systematic review.

Note on the author: Dr Pamela Katic is a Senior Social Scientist at the Natural Resources Institute of the University of Greenwich. She has extensive experience in environmental economic modelling and co-development of research with indigenous peoples, in relation to water and marine management, agroforestry systems and nutrition-sensitive interventions. She currently leads the Newton Fund project on 'Intercultural models to improve nutrition and health of indigenous populations through agroforestry' in Peru, the British Academy project on 'Enhancing value added products and nutritional benefits from agroforestry systems' in Peru, and the UKRI-funded project on 'Diversifying aquaculture systems to improve the resilience of UK food systems'. Dr Katic is a member of Future Earth's UK National Committee and of FAO's Global Hub of Indigenous Peoples' Food Systems.

https://orcid.org/0000-0001-7594-1081

p.g.katic@gre.ac.uk

(C) The author(s) 2021. This is an open access article licensed under a

Creative Commons Attribution-NonCommercial-NoDerivs 4.0 Unported License 


\section{Introduction}

Agroforestry, broadly defined as an agricultural land use where crops, livestock, and fish production are managed in association with trees to enhance ecosystem services, has been widely promoted as one of the most efficient sustainable land management practices in terms of its simultaneous contribution to address desertification, land degradation and drought, declining biodiversity, and accelerated climate change. The concept of agroforestry was from its very beginning aligned with 'restoration' and linking farmers' knowledge, objectives, and expectations to desirable environmental change. Where earlier definitions of agroforestry focused on the technology of plot-level integration of trees at field and farm level, subsequent interpretations of agroforestry as an element of multifunctional landscapes, have focussed on the agriculture/forest interface at landscape and livelihoods scales. Finally, in the late 2000s-early 2010s, the lack of recognition of the active interface of agriculture and forestry became the basis for defining agroforestry as a domain for coherent policies for all land uses, to achieve the higher-level Sustainable Development Goals (van Noordwijk \& Coe 2019).

Issued at the conclusion of the 4th World Congress of Agroforestry in 2019, the 'Montpellier Declaration: Make our Planet Treed Again!' highlights the multiple benefits of agroforestry, including its role in maintaining or enhancing yields while mitigating carbon emissions, adapting to the increasingly frequent droughts and floods linked to climate change, restoring degraded soils, and maximising the overall productivity of landscapes for humanity and nature (International Institute for Sustainable Development 2019). Advancing agroforestry in the policy and scientific agenda is particularly beneficial as these practices significantly depart from conventional coping strategies and incremental adaptation to climate change, which may not always be effective at helping people or ecosystems to reduce their vulnerabilities to climatic changes. Instead, agroforestry fundamentally alters the entire system's ecological and/or social properties and functions, thus reducing the root causes of vulnerabilities to climate change (Fedele et al. 2019).

A new appreciation of the relevance of agroforestry and related practices for the climate change agenda is emerging as part of the recent IPCC (Intergovernmental Panel on Climate Change) land-use report (Smith et al. 2019). The 2019 update of the IPCC guidelines for national greenhouse gas inventories for the first time explicitly includes default data (for Tier 2 accounting) for a range of agroforestry land uses (Cardinael et al. 2018, Ogle et al. 2019). National Adaptation Plans increasingly make explicit reference to agroforestry (Meybeck et al. 2020). While trees on farms around the world have been steadily increasing, adoption of agroforestry is mostly limited to a minority of innovative land-users and practitioners (Sanz et al. 2017). A 'transformative change' is needed to speed up the adoption of agroforestry systems. 
From 1990 to 2018, almost ten times more funding for climate change research went to the natural and technical sciences than to the social sciences and humanities (Overland \& Sovacool 2020). But we will not solve problems related to land, trees, and forests contributing to our global crises if we do not understand and address the governance challenges (Maryudi et al. 2018). Governance research is essential to understanding how to bring about transformational change in policies, institutions, and behaviours (Rahman et al. 2018). For forests and trees, governance is relevant across scales (from global policies and challenges to local land use practices) and is inherently multi-actor and multilevel. However, governance structures often do not encourage cross-sectoral and cross-scale planning and cause instability over time. The inability to accommodate traditional governance mechanisms and access rights recognised by indigenous people and local communities can further limit agroforestry from catalysing transformative adaptation (Scherr et al. 2012). As agroforestry redefines entire systems and alters both social and ecological processes, it becomes critical to identify the changes required in governance structures to facilitate this type of adaptation (Fedele et al. 2019).

While there have been recent syntheses focused on the climate-related benefits of agroforestry (Brown et al. 2018), there has not been a comprehensive literature review and synthesis focused on climate change governance of agroforestry systems. We aim to address this gap in the literature by applying a systematic review methodology with five objectives: (1) outline the current state of the literature, (2) characterise how governance is conceptualised, (3) investigate governance challenges, and (4) provide insights into effective governance. The paper begins with an overview of the methods, followed by the results and discussion, and, finally, presents the main conclusions that can be drawn from the research.

\section{Methodology}

We employ a systematic review of literature related to climate change governance and agroforestry, where we sample, analyse, and synthesise literature to answer targeted research questions. We follow a four-step process as follows: (1) determine research questions to guide the review; (2) develop a search protocol (that is, targeted databases and search terms) to explore literature databases; (3) screen the results of the literature search based on a predetermined set of criteria; and (4) conduct an analysis and synthesis of the remaining literature.

The questions guiding our research relate directly to the objectives (Table 1). Governments, the private sector, and civil society need to have a better, contextually grounded, understanding of options for achieving effective and inclusive governance of forests and trees and promote biodiversity-enhancing agricultural systems, such as 
Table 1. Objectives and related research questions.

\begin{tabular}{ll}
\hline Objective & Research question $(s)$ \\
\hline $\begin{array}{l}\text { To outline the state of the literature on climate } \\
\text { change governance in agroforestry settings }\end{array}$ & $\begin{array}{l}\text { What are the main characteristics of relevant } \\
\text { publications (e.g., geographic focus)? }\end{array}$ \\
$\begin{array}{ll}\text { To characterise the current conceptualisation of } \\
\text { climate change governance within the literature }\end{array}$ & $\begin{array}{l}\text { Is climate change governance defined? If so, what } \\
\text { definitions are used? }\end{array}$ \\
& $\begin{array}{l}\text { If not, how is climate change governance being } \\
\text { constructed? }\end{array}$ \\
$\begin{array}{ll}\text { To investigate the challenges of climate change } \\
\text { governance and provide insights into what is }\end{array}$ & $\begin{array}{l}\text { What governance challenges emerge from, or are } \\
\text { apparent in the literature? }\end{array}$ \\
$\begin{array}{l}\text { What characteristics and factors emerging from the } \\
\text { agroforestry settings }\end{array}$ & $\begin{array}{l}\text { literature are thought to constitute effective } \\
\text { governance? }\end{array}$ \\
\hline
\end{tabular}

agroforestry, that can contribute to climate change mitigation without compromising yields. For governance to support this by aligning incentive structures, reimagining accountability systems and levelling the playing field, a governance research agenda must be based on an initial understanding of the paradigms used and the research insights that support transformational change.

While we recognise that grey literature, particularly in the form of reports published by multinational or research organisations related to climate change and agroforestry issues, may be relevant to the purposes of this review, we chose to focus only on published literature to keep the review task manageable (in the face of an overwhelming volume of academic literature) and to validate the quality of the articles reviewed through a peer-review process. Future studies may consider including grey literature to address individual study limitations through contextualisation and triangulation, while treating different categories of evidence separately. We chose Scopus as the targeted database because it contains a broad range of journals related to agroforestry management and climate governance. This database is appropriate since: (1) the relevant literature spans multiple disciplines (for example, ecology, geography, sociology, planning) and (2) there are no journals or databases focused specifically on agroforestry or climate governance. These two conditions necessitate drawing from a range of journals and databases to capture an adequate scope of relevant papers.

The targeted databases were queried using two sets of keywords relating to: (1) definitions and terms used to describe agroforestry systems, (2) terms that explicitly contained the concepts of climate change governance or climate governance (Table 2). We acknowledge that these search terms would omit relevant publications that do not explicitly use the term 'governance'. However, we assume that explicit use of the term 'governance' is important, since we aim to explore governance conceptualisations, challenges, and effectiveness. 
Table 2. Search terms by category.

\begin{tabular}{|c|c|}
\hline Category & Terms \\
\hline Agroforestry systems & 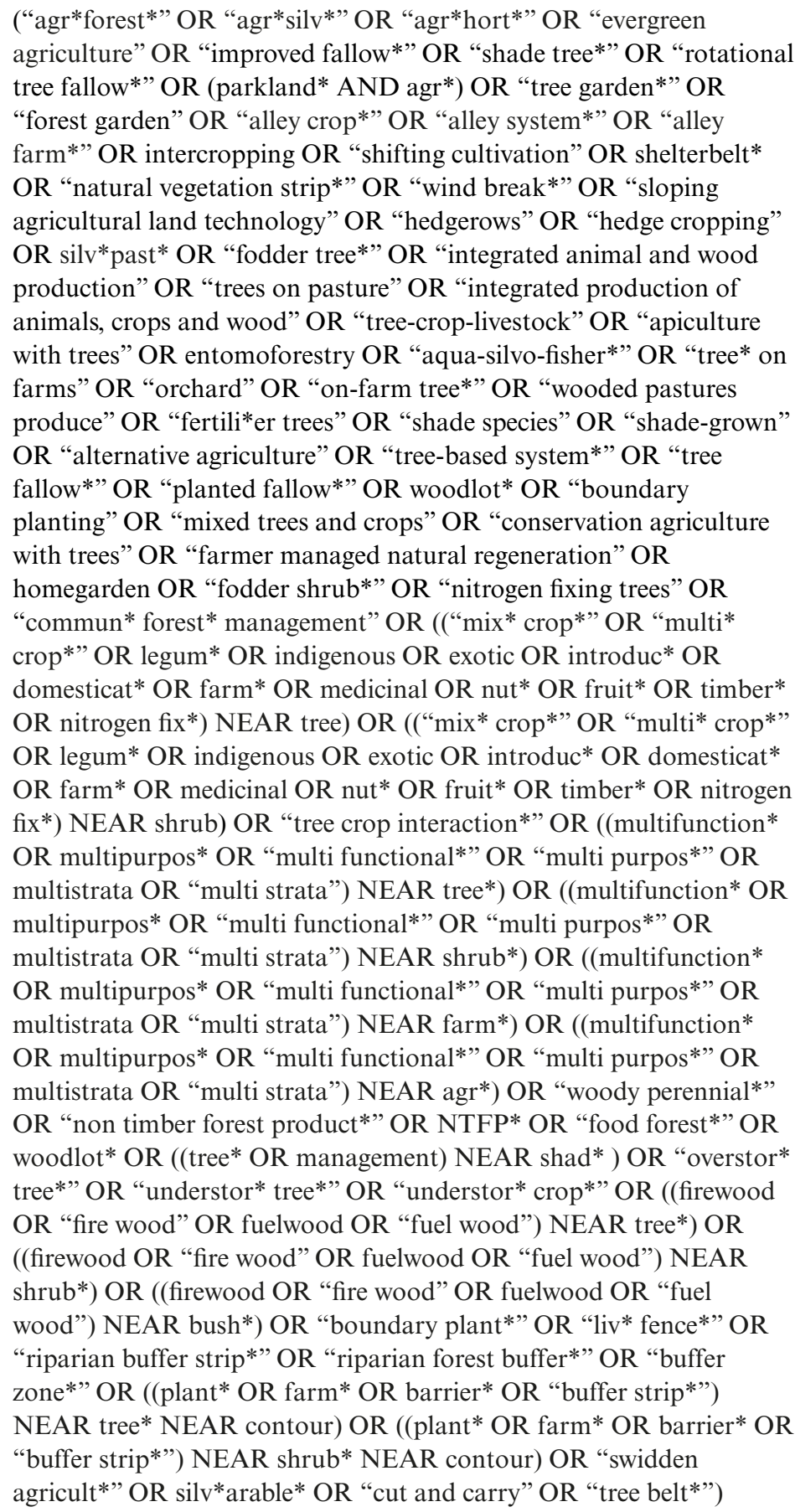 \\
\hline Climate change governance & ("climat* governance" OR "climat* chang* governance") \\
\hline
\end{tabular}


The search protocol returned 312 papers. These papers were then screened employing the following criteria: (1) papers must be peer-reviewed; (2) papers must be written in English; and (3) papers must be published during or after 1999, since our focus is on contemporary literature. While it is recognised that several agroforestry studies are performed by not-for-profit, private, and government organisations, and that grey literature is a relevant tool for understanding information, this review's focus on peer-reviewed academic literature enables a discussion on the research direction emerging within the academic field. The articles were then filtered at two different stages of detail, each filter excluding studies that were irrelevant to the research objective. The first filter consisted of a review of each abstract, which demonstrated a clear effort on the assessment of climate-related governance in agricultural and/or forested landscapes, after which we obtained 192 scientific papers. The second filter consisted of a thorough analysis of the full publication. Governance components under scrutiny needed to be clearly stated and an agroforestry operation had to discussed. Sixty-four papers remained after screening.

Following the final selection of papers, information was manually extracted from articles. Qualitative synthesis of extracted features was then used to analyse patterns, interpretations, and gap analysis. Coded features were distributed across the three objectives of the study: (1) the state of the literature, (2) the conceptualisation of climate change governance, and (3) the challenges and effectiveness of climate change governance within agroforestry settings (Table 3 ).

Table 3. Features extracted from peer-reviewed scientific journals during systematic literature review.

\begin{tabular}{|c|c|c|}
\hline Research objective & Extracted feature & Specific categorisations \\
\hline \multirow[t]{6}{*}{ The state of the literature } & Year of publication & Year \\
\hline & Journal of publication & Name of journal \\
\hline & Academic discipline & $\begin{array}{l}\text { Field(s) of study relevant to the citing } \\
\text { journal }\end{array}$ \\
\hline & Location of study & $\begin{array}{l}\text { The country (or region) where the } \\
\text { study was conducted }\end{array}$ \\
\hline & Agroforestry system type & $\begin{array}{l}\text { Details of agroforestry system } \\
\text { mentioned }\end{array}$ \\
\hline & Study type & $\begin{array}{l}\text { Modelling, review, theoretical, } \\
\text { methodological, empirical }\end{array}$ \\
\hline $\begin{array}{l}\text { The conceptualisation of } \\
\text { climate change governance }\end{array}$ & Definition & $\begin{array}{l}\text { Definition used or implied of } \\
\text { governance }\end{array}$ \\
\hline \multirow[t]{2}{*}{$\begin{array}{l}\text { The challenges and } \\
\text { effectiveness of governance }\end{array}$} & Challenges of governance & $\begin{array}{l}\text { Identification and categorisation of } \\
\text { challenges to governance } \\
\text { effectiveness }\end{array}$ \\
\hline & Effectiveness of governance & $\begin{array}{l}\text { Identification and categorisation of } \\
\text { factors contributing to governance } \\
\text { effectiveness }\end{array}$ \\
\hline
\end{tabular}




\section{Results and discussion}

This section covers the main findings of the review and discusses their implications. The section is organised according to the objectives (Table 1).

\subsection{The state of the literature}

The majority of papers included in the sample were published since 2013, with 2019 and 2020 accounting for more than half of the sample (Figure 1). The literature is also found in a diverse set of journals. There were two individual journals (Forest Policy and Economics and Sustainability (Switzerland)) that each contained more than two papers within the sample. In addition to these two journals, there were eight journals that each published two papers in the sample and thirty-six journals that each published one. While the majority of the papers were from social science ( 28 per cent) or environmental science (35 per cent) journals, the journals' foci ranged widely and included economic and agricultural science journals.

Approximately 41 per cent of papers were review papers. However, 22 per cent were review papers that drew on case studies to demonstrate their findings (that is, they included case studies but did not report on specific methods for gathering data and examining the case studies). Approximately 44 per cent were empirical papers and

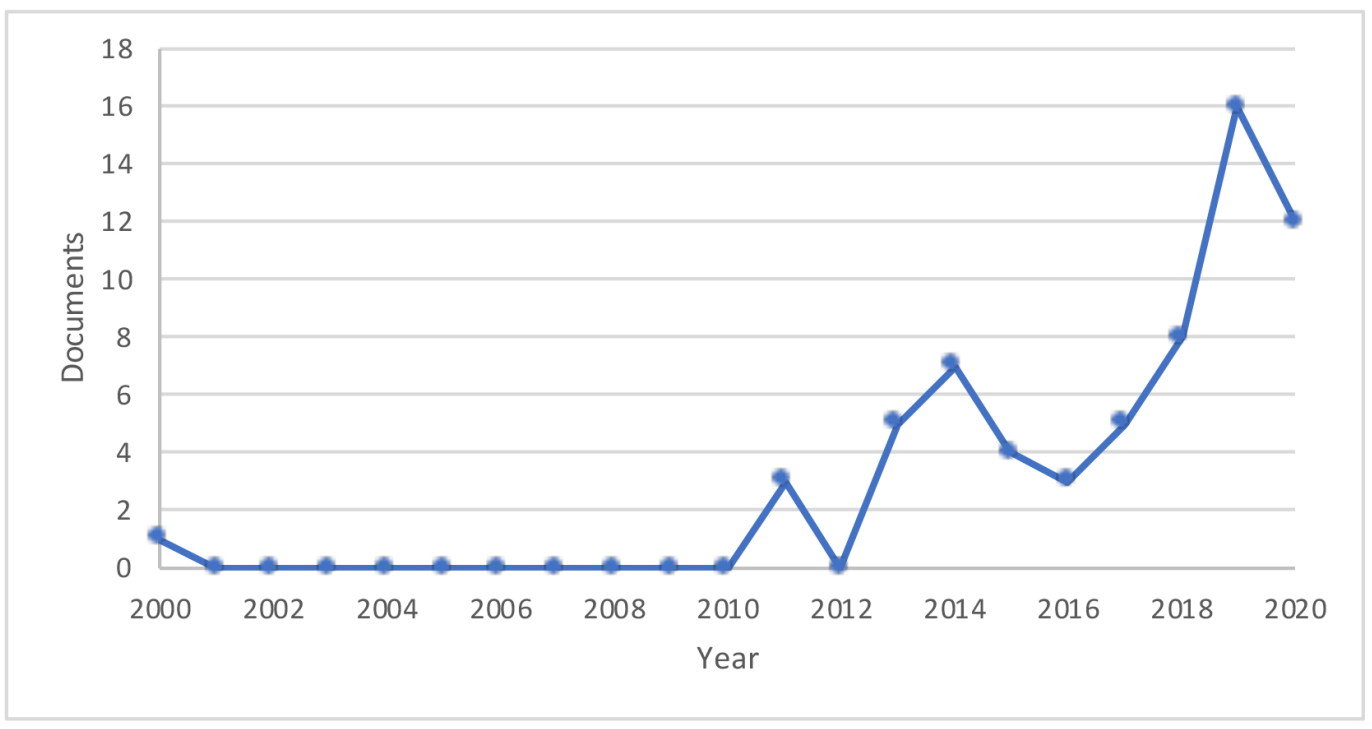

Figure 1. Documents by year. 
15 per cent were conceptual papers. The geographic range for empirical and review papers using case studies was varied. However, there were considerably more papers focused on Indonesia $(n=7)$ than on other countries.

\subsection{The conceptualisation of climate change governance}

It is important to note that, except for Kunz et al. (2019), who define climate change governance as the 'purposeful mechanisms and measures aimed at steering social systems towards preventing, mitigating, or adapting to the risks posed by climate change', none of the literature sampled provided a definition. The sampled literature, rather, exhibits two main implicit conceptualisations of governance: (1) governance as context; and (2) governance as praxis. Each has different implications for how climate change can be addressed.

With regard to 'context', governance is considered part of the setting in which the climate responsive management of the agriculture-forest interactions takes place (e.g., Sahide et al. 2020). Thus, governance is seen largely as a structural phenomenon, consisting of rules, regulations, regimes, and the institutional arrangements that enable and constrain management (Jodoin 2020, Singh et al. 2020). There are clear lines drawn between governance and management in this perspective, and sometimes the two are cast as having an antagonistic relationship. For example, this literature often asserts that effective sustainable land management practices like agroforestry require converging governance structures that keep agriculture, forestry, and climate change separate (Soto Golcher \& Visseren-Hamakers 2018). However, using a 'governance as context' perspective may limit needed attention to the processes required to mainstream or contextualise different management approaches in agroforestry landscapes.

Governance as praxis moves beyond a contextual focus to include attention to process. Governance, under this construct, still contains structural components (for example, rules, regulations, arrangements); however, it is also active and reflexive with a greater attention to the people or actors who are involved in governing and recognising the importance of all governance levels, thus pointing to a polycentric nature of governance (Ruseva et al. 2020). The lines between governance and management are somewhat blurred, and the two are considered to contribute synergistically to desired outcomes. For example, the ability to mainstream biodiversity in productive sectors under climate change is viewed as contingent upon determining effective agroforestry governance networks and actor interactions related to information exchange, finance flows, and regulation (Zinngrebe et al. 2020).

If the paper described institutions and decision-making rules without engaging with populations around their decision processes on natural resource management, 
then the paper was categorised as analysing governance as context. Otherwise, it was categorised as employing the concept of governance as praxis. The latter was the most common construct with 43 per cent of papers invoking it. Governance as context was apparent in 36 per cent of papers. The remainder of the papers either did not invoke either construct (that is, governance as praxis or context) or did not provide enough information to make an adequate judgement.

\subsection{The challenges of climate change governance within agroforestry settings}

There were three main challenges identified through the systematic review: (1) coordinating polycentricity; (2) overcoming power imbalances; and (3) sharing, translating, and integrating different types of knowledge. These three challenges were each found in approximately 70 per cent of papers. There were three other challenges identified: (1) dealing with uncertainty about future climate or social conditions; (2) negotiating trade-offs among different sectors or resource users; and (3) debunking persistent problem frames. These challenges were less predominant in the literature and were only found in between 20 and 50 per cent of papers. The most predominant challenges are discussed further below.

The first challenge that emerged from the systematic review deals with fostering partnerships and polycentric governance structures. Transformative climate change adaptation by fundamentally changing the characteristics and properties of land use through agroforestry may be discouraged by the need to involve multiple stakeholders, sectors, and governance levels with potentially different interests (Fedele et al. 2019). For example, in the context of REDD+ programmes in Indonesia, REDD+ institutions that have been built at the national level have not yet been realised at the sub-national level, resulting in differences in achievement. In addition, conflicting policies among the forestry, plantation, and mining sectors mean that agroforestry projects supported by REDD+ often compete with other major land-based developments (Ekawati et al. 2019). On the role of the private sector, Carodenuto (2018) has shown how these stakeholders have entered into partnerships with the government to help the state create supply chain transparency. As a result, 'business would simultaneously play the role of regulator and regulated, which may shift incentives to dilute or generously interpret how certain aspects of zero deforestation definitions are applied in the field'. The challenge of governance becomes fostering partnerships and polycentric structures (for example, commodity chains, mixed management committees, etc.) that connect multiple spatial and jurisdictional scales while dismantling perverse incentives and strengthening business and government accountability (Delabre et al. 2020). Climate change adds urgency to the need to coordinate multiple centres of decision-making, but also an extra dimension to the challenge. The challenge 
becomes scaling up and recognising the planetary issue of forests and climate change, while simultaneously scaling down to empower social actors (for example, farmers organisations) at scales relevant to them.

In addition to dealing with polycentricity, climate governance in agroforestry settings must also - according to the sampled literature - overcome power imbalances (Ojha 2019). For example, Delabre et al. (2020: 1-2) note how conventional approaches to governing forests and promoting agroforestry are 'locked-in by discursive, institutional and material expressions of power premised upon an historical colonial legacy that enables private investments in forest lands and the exploitation of forest resources around the world'. Governance may indeed succeed in changing some of the formal and visible institutional forms, but subtle power relations and socio-political differentiations within local communities and the political arena tend to persist (Wong et al. 2019). If not part of a wider political project or empowerment, 'technical "participatory" practices may interact with existing inequalities, norms and power dynamics and risk further disempowerment of marginalized peoples' (Delabre et al. 2020: 7). The challenge of governance becomes underpinning a multilevel and multidimensional forest governance system by participation and deliberative processes, with decentralisation and community empowerment being part of larger deliberative and democratic systems.

An additional governance challenge identified within the sampled literature is sharing, translating, and integrating different types of knowledge in governance structures. As Zinngrebe et al. (2020: 1419) point out, 'in agroforestry systems, mono-directional knowledge flows from technical experts to project managers and farmers can be a barrier to innovation as collective exploration processes are needed to find solutions responding to contexts and local perceptions'. A nuanced understanding of local-level dynamics and complexities involves engaging knowledge from forest dwellers in the co-production of assessments and decisions about their implications (Delabre et al. 2020, Schroeder \& Gonzàlez 2019). However, forestry in some governance systems is a 'realm in which scientific and local knowledge systems meet on unequal footing' (Carton 2020: 1364). These pre-existing foci create barriers to using plural lenses and recognising diverse indigenous, scientific, and experiential knowledge. The challenge of governance becomes developing suitable processes for engaging with diverse sources and types of knowledge.

\subsection{The effectiveness of governance}

The literature we reviewed recognised six factors contributing to governance effectiveness in making progress towards addressing the main challenges highlighted above: (1) science-policy integration, (2) context fit, (3) supportive agroforestry 
governance networks, (4) reciprocal exchanges of information (both between actors and between political levels), (5) strong and accountable business and government leadership, and (6) diverse and inclusive co-creating mechanisms that account for heterogeneity at community level. These notions of effectiveness were usually seen as cross-cutting in relation to the challenges identified. The most predominant factor was policy and science integration, which was apparent in approximately 80 per cent of the papers, followed by context fit, which was apparent in 70 per cent. The other four factors were all similarly predominant and apparent in approximately 30-60 per cent of papers. Only the two most predominant notions of effectiveness will be discussed in detail below.

The fragmentation of governance processes (vertically and horizontally) for agroforestry was a strong barrier for mainstreaming biodiversity into productive sectors. With the prospect of new finance opportunities from sustainable value chains or international finance instruments, such as REDD+, possible incentives for agroforestry will depend on the coordination of climate and biodiversity policies, as well as the integration of institutional settings within existing governance structures while reducing administrative hurdles (Zinngrebe et al. 2020). In the case of governance systems dominated by one regime, as is the case in climate change, integration might have greater potential outside the intergovernmental regime through soft law approaches (Soto Golcher \& Visseren-Hamakers, 2018).

Science-policy integration usually refers to the use of scientific knowledge when making policy. A key ingredient of successful science-policy integration appears to be a focus on interdisciplinary or transdisciplinary science, which facilitates access to diverse forms of knowledge. As Delabre et al. (2020: 7) articulate, 'this unity between science, indigenous knowledge, gendered understandings of forest politics and other alternative voices in proactive (counter)action provides opportunities for weakening the perpetuation of dominant myths (of sustainable forest governance) by allowing for a variety of values, knowledges and cultures to inform forest policy'.

We refer to context fit as the ability of governance to account for the socio-ecological characteristics, processes, and dynamics of the agroforestry systems being influenced by governance. Within the literature, context fit usually involves developing and enforcing progressive laws and regulatory frameworks suited to context (Delabre et al. 2020) and recognising traditional indigenous ontologies of territoriality (Schroeder \& Gonzàlez 2019). However, the ability of governance to achieve context fit is often constrained by pre-existing institutional capacity and social conditions, such as existing jurisdictions or sector-based management. Further empirical work is needed on the role of agroforestry governance networks in linking and balancing different types of context knowledge, and how these relate to governance effectiveness under conditions of change (Hasnaoui \& Krott 2019). 


\section{Conclusions}

The literature on climate change governance across agroforestry systems has flourished over the last couple of years. This literature has been found in a number of interdisciplinary journals. Governance is conceptualised mostly as praxis, but also commonly as context. Coordinating polycentricity, overcoming power imbalances, and sharing, translating, and integrating different types of knowledge are the most commonly found governance challenges within the literature, while the need for science-policy integration and context fit are the most commonly cited elements of effective governance.

Currently, few papers treat governance of agroforestry systems - as transformative adaptations to climate change - as theory (that is, a set of propositions and hypotheses to be empirically tested), and there is no unique or distinct definition of governance in this context. This points to a need to develop a richer conceptual framework of governance that accounts for the direct social and ecological linkages and feedbacks between restructured livelihood activities and multi-scale environmental and socioeconomic realms. Ongoing conceptual development in the areas of institutional adaptation, agroforestry governance networks, and social-ecological fit may be sources of innovation to foster meaningful and beneficial governance in this context.

This article has shown that the imperative to catalyse more effective and adaptive forms of governance is increasingly evident. Governance is an important component of our ability to navigate transformative adaptation to rapid social and environmental change, and developing a more in depth and appropriate understanding of governance of agroforestry systems is crucial to promoting sustainability as we negotiate current and future change.

\section{References}

Brown, S.E., Miller, D.C., Ordonez, P.J. \& Baylis, K. (2018), 'Evidence for the Impacts of Agroforestry on Agricultural Productivity, Ecosystem Services, and Human Well-being in High-income Countries: A Systematic Map Protocol', Environmental Evidence, 7(1): 1-16. https://doi.org/10.1186/s13750-018-0136-0

Cardinael, R., Umulisa, V., Toudert, A., Olivier, A., Bockel, L. \& Bernoux, M. (2018), 'Revisiting IPCC Tier 1 Coefficients for Soil Organic and Biomass Carbon Storage in Agroforestry Systems', Environmental Research Letters, 13(12): 124020. https://doi.org/10.1088/1748-9326/aaeb5f

Carodenuto, S. (2019), 'Governance of Zero Deforestation Cocoa in West Africa: New Forms of Public-Private Interaction', Environmental Policy and Governance, 29(1): 55-66. https://doi.org/10.1002/eet.1841

Carton, W. (2020), 'Rendering Local: The Politics of Differential Knowledge in Carbon Offset Governance', Annals of the American Association of Geographers, 110(5): 1353-68. https://doi.org/10.1080/24694452.2019.1707642 
Delabre, I., Boyd, E., Brockhaus, M., Carton, W., Krause, T., Newell, P., Wong, G.Y. \& Zelli, F., (2020), 'Unearthing the Myths of Global Sustainable Forest Governance', Global Sustainability, 3: e16. https://doi.org/10.1017/sus.2020.11

Ekawati, S., Subarudi, Budiningsih, K., Sari, G.K. \& Muttaqin, M.Z. (2019), 'Policies Affecting the Implementation of REDD+ in Indonesia (Cases in Papua, Riau, and Central Kalimantan)', Forest Policy and Economics, 108: 101939. https://doi.org/10.1016/j.forpol.2019.05.025 https://doi.org/10.1016/j.forpol.2019.05.025

Fedele, G., Donatti, C.I., Harvey, C.A., Hannah, L. \& Hole, D.G. (2019), 'Transformative Adaptation to Climate Change for Sustainable Social-Ecological Systems', Environmental Science \& Policy, 101: 116-25. https://doi.org/10.1016/j.envsci.2019.07.001

Hasnaoui, A. \& Krott, M. (2019), Optimizing State Forest Institutions for Forest People: A Case Study on Social Sustainability from Tunisia', Sustainability, 11(7): 1954. https://doi.org/10.3390/su11071954

International Institute for Sustainable Development (2019), Agroforestry Congress, ICRAF/FAO Publications Call for Transformation of Global Food System. https://sdg.iisd.org/news/ agroforestry-congress-icraffao-publications-call-for-transformation-of-global-food-system/

Jodoin, S. (2019), 'Transnational Legal Process and Discourse in Environmental Governance: The Case of REDD+ in Tanzania', Law \& Social Inquiry, 44(4): 1019-50. https://doi.org/10.1017/1si.2019.7

Kunz, Y., Otten, F., Mardiana, R., Martens, K., Roedel, I. \& Faust, H. (2019), 'Smallholder Telecoupling and Climate Governance in Jambi Province, Indonesia', Social Sciences, 8(4): 115. https://doi.org/10.3390/socsci8040115

Maryudi, A., Acheampong, E., Rutt, R.L., Myers, R. \& McDermott, C.L. (2020), “"A Level Playing Field"? What an Environmental Justice Lens Can Tell us about Who Gets Leveled in the Forest Law Enforcement, Governance and Trade Action Plan', Society \& Natural Resources, 33(7): 859-75. https://doi.org/10.1080/08941920.2020.1725201

Meybeck, A., Gitz, V., Wolf, J. \& Wong, T. (2020), 'Addressing Forestry and Agroforestry in National Adaptation Plans' (Bogor, FTA; Rome, FAO). https://doi.org/10.4060/cb1203en

Ogle S.M., Wakelin, S.J., Buendia, L., McConkey, B., Baldock, J., Akiyama, H., Kishimoto-Mo, A.W., Chirinda, N., et al. (2019), 'Cropland', in 2019 Refinement to the 2006 Guidelines for National Greenhouse Gas Inventories, Vol. 4, Agriculture, Forestry and Other Land Use (IPCC), Chapter 5. https://www.ipcc.ch/report/2019-refinement-to-the-2006-ipcc-guidelines-for-national-greenhouse-gas-inventories/ https://doi.org/10.21513/0207-2564-2019-2-05-13

Ojha, H., Maraseni, T., Nightingale, A. \& Bhattarai, B. (2019), 'Rescuing Forests from the Carbon Trap', Forest Policy and Economics, 101: 15-18. https://doi.org/10.1016/j.forpol.2019.01.007

Overland, I. \& Sovacool, B.K. (2020), 'The Misallocation of Climate Research Funding', Energy Research \& Social Science, 62: 101349. https://doi.org/10.1016/j.erss.2019.101349

Rahman, M.S., Sarker, P.K., Sadath, M.N. \& Giessen, L. (2018), 'Policy Changes Resulting in Power Changes? Quantitative Evidence from 25 Years of Forest Policy Development in Bangladesh', Land Use Policy, 70: 419-31. https://doi.org/10.1016/j.landusepol.2017.11.029

Ruseva, T., Hedrick, J., Marland, G., Tovar, H., Sabou, C. \& Besombes, E. (2020), 'Rethinking Standards of Permanence for Terrestrial and Coastal Carbon: Implications for Governance and Sustainability', Current Opinion in Environmental Sustainability, 45: 69-77. https://doi.org/10.1016/j.cosust.2020.09.009

Sahide, M.A.K., Fisher, M.R., Erbaugh, J.T., Intarini, D., Dharmiasih, W., Makmur, M., Faturachmat, F., Verheijen, B. \& Maryudi, A. (2020), 'The Boom of Social Forestry Policy and the Bust of Social Forests in Indonesia: Developing and Applying an Access-Exclusion Framework to Assess Policy Outcomes', Forest Policy and Economics, 120: 102290.

https://doi.org/10.1016/j.forpol.2020.102290 
Sanz, M.J., de Vente, J., Chotte, J.-L., Bernoux, M., Kust, G., Ruiz, I., Almagro, M., Alloza, J.-A., Vallejo, R., Castillo, V., Hebel, A. \& Akhtar-Schuster, M. (2017), 'Sustainable Land Management Contribution to Successful Land-based Climate Change Adaptation and Mitigation. A Report of the Science-Policy Interface. (Bonn, United Nations Convention to Combat Desertification (UNCCD)). https://www.unccd.int/sites/default/files/documents/2017-09/UNCCD_Report_SLM.pdf

Scherr, S.J., Shames, S. \& Friedman, R. (2012), 'From Climate-smart Agriculture to Climate-smart Landscapes’, Agriculture \& Food Security, 1: 12. https://doi.org/10.1186/2048-7010-1-12

Schroeder, H. \& González, N.C. (2019), Bridging Knowledge Divides: The Case of Indigenous Ontologies of Territoriality and REDD+', Forest Policy and Economics, 100: 198-206. https://doi.org/10.1016/j.forpol.2018.12.010

Singh, C., Ford, J., Ley, D., Bazaz, A. \& Revi, A. (2020), 'Assessing the Feasibility of Adaptation Options: Methodological Advancements and Directions for Climate Adaptation Research and Practice', Climatic Change, 162(2): 255-77. https://doi.org/10.1007/s10584-020-02762-x

Smith, P., Calvin, K., Nkem, J., Campbell, D., Cherubini, F., Grassi, G., Korotkov, V., Le Hoang, A., Lwasa, S., McElwee, P. \& Nkonya, E. (2019), 'Which Practices Co-deliver Food Security, Climate Change Mitigation and Adaptation, and Combat Land Degradation and Desertification?', Global Change Biology, 26(3): 1532-75. https://doi.org/10.1111/gcb.14878

Soto Golcher, C. \& Visseren-Hamakers, I.J. (2018), 'Framing and Integration in the Global Forest, Agriculture and Climate Change Nexus', Environment and Planning C: Politics and Space, 36(8): 1415-36. https://doi.org/10.1177/2399654418788566

van Noordwijk, M. \& Coe, R. (2019), 'Agroforestry Paradigms', in M. van Noordwijk (ed.) Sustainable Development through Trees on Farms: Agroforestry in its Fifth Decade (Bogor, World Agroforestry (ICRAF)), 3-14.

Wong, G.Y., Luttrell, C., Loft, L., Yang, A., Pham, T.T., Naito, D., Assembe-Mvondo, S. \& Brockhaus, M. (2019), 'Narratives in REDD+ Benefit Sharing: Examining Evidence Within and Beyond the Forest Sector', Climate Policy, 19(8): 1038-51. https://doi.org/10.1080/14693062.2019.1618786

Zinngrebe, Y., Borasino, E., Chiputwa, B., Dobie, P., Garcia, E., Gassner, A., Kihumuro, P., Komarudin, H., Liswanti, N., Makui, P. \& Plieninger, T. (2020), 'Agroforestry Governance for Operationalising the Landscape Approach: Connecting Conservation and Farming Actors', Sustainability Science, 15(5): 1417-34. https://doi.org/10.1007/s11625-020-00840-8

To cite the article: Pamela Katic (2021), 'Climate change governance in agroforestry systems: a systematic review', Journal of the British Academy, 9(s10): 7 -20. DOI https://doi.org/10.5871/jba/009s10.007

Journal of the British Academy (ISSN 2052-7217) is published by The British Academy, 10-11 Carlton House Terrace, London, SW1Y 5AH www.thebritishacademy.ac.uk 